\title{
Intervertebral disc calcification in children
}

\section{KG Magnus}

BSC(UCT), MBChB(UCT), MMed(RadD, Stell)

Department of Paediatric Radiology, Red Cross War Memorial Children's Hospital, Cape Town

\section{Abstract}

Symptomatic cervical intervertebral disc calcification in children presents with characteristic signs and symptoms, and usually has a benign, self-limiting and predictable course. The radiological images of the spine likewise have typical appearances, with a recognisable pattern and following a predetermined course. A case report of this uncommon condition in an 8-year-old boy illustrates most of the clinical and radiological findings in this entity.

\section{Introduction}

Intervertebral disc calcification (IVDC) is uncommon in children. ${ }^{1-13}$ First described by Baron in $1924,{ }^{14}$ numerous articles have since appeared. Few of these reports have appeared in the radiological literature, and the majority of these have been published in paediatric radiology journals. The aim of this article is to bring this uncommon but important subject to the attention of all radiologists.

\section{Case report}

A 10-year-old boy presented at Red Cross Children's Hospital with a two-day history of an extremely painful neck. The onset was spontaneous and was not associated with any injury. Dysphagia without regurgitation of food had been periodically experienced. No other symptoms were elicited from the patient.

Examination revealed a wellgrown, apyrexial boy with a marked torticollis. The patient's head was tilted and rotated to the left as a result of severe left-sided sternocleidomastoid muscle spasm. Any form of head or neck movement produced acute neck pain and consequently mobility was totally restricted. Both upper limbs were neurologically normal, with no evidence of radiculopathy. An ear, nose and throat examination was normal.

Plain x-rays of the cervical spine were performed at the time of the initial consultation. The anteroposterior (AP) (Figure 1) and lateral (Figure 2)

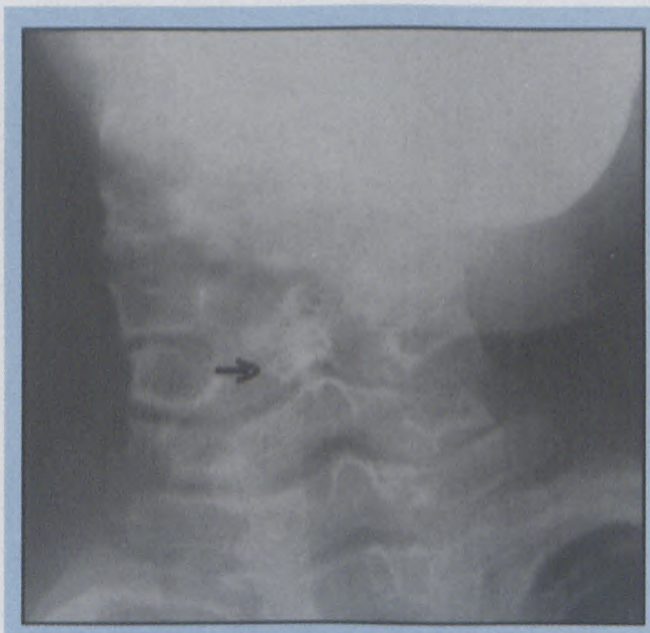

Figure 1: AP cervical spine $x$-ray. Chin tilted and rotated to the left. Scoliosis convex to the right. Dense, oval shaped, central calcified intervertebral disc (arrow) at C5/6 level. 


\section{from page 8}

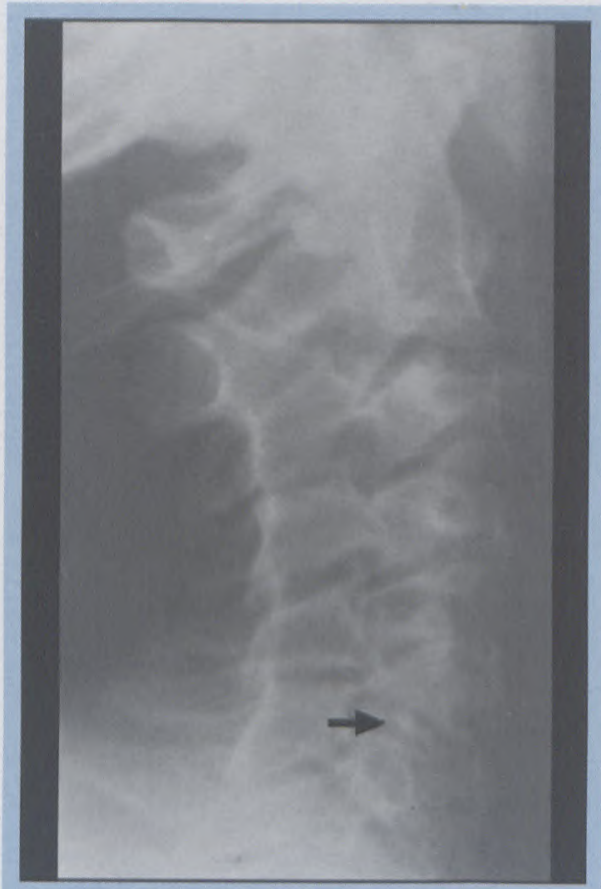

Figure 2: Lateral cervical spine $x$-ray. The slight rotation and scoliosis results in poor lateral positioning. Linear, layered, densely calcified C5/6 intervertebral disc (arrow). Anterior wedging of the C5 vertebral body also present.

projections demonstrated scoliosis convex to the right, with tilting and rotation of the head towards the left, plus dense, irregular, layered calcification of the intervertebral disc at the C5/C6 level. Loss of height of the anterior $\mathrm{C} 5$ vertebral body was present, giving it a wedge shape. The paravertebral soft tissues plus the remainder of the cervical vertebral bodies and their posterior elements were normal in appearance.

Computed tomography (CT) of the cervical spine followed the plain $\mathrm{x}$-rays. CT confirmed the dense calcification in the nucleus pulposus of the C5/C6 intervertebral disc (Figure 3). Unsuspected central posterior herniation of the calcified nucleus pulposus through the annulus fibrosis was present, with slight midline protrusion of the calcified material into the spinal canal. The subligamentous (anterior to the posterior longitudinal ligament) calcified disc herniation indented the dural sac without compressing the spinal cord. Sagittal reconstruction confirmed the anterior wedging of the vertebral body of C5. The remainder of the vertebral bodies and their posterior elements, as well as the surrounding paraspinal soft tissue structures appeared normal. Scoliosis and rotation of the cervical spine were confirmed.

Non-steroidal anti-inflammatory drugs plus analgesic medication were instituted for a month. The patient's neck was immobilised in a soft cervical collar. All vigorous activity was suspended. At the follow-up consultation two weeks later, the patient was totally pain-free and clinically normal in appearance. The patient remained symptom-free and normal on examination at a further follow-up examination three months later. Repeat AP (Figure 4) and lateral (Figure 5) cervical spine $\mathrm{x}$-rays on this occasion showed normal alignment. The previously noted dense calcification in

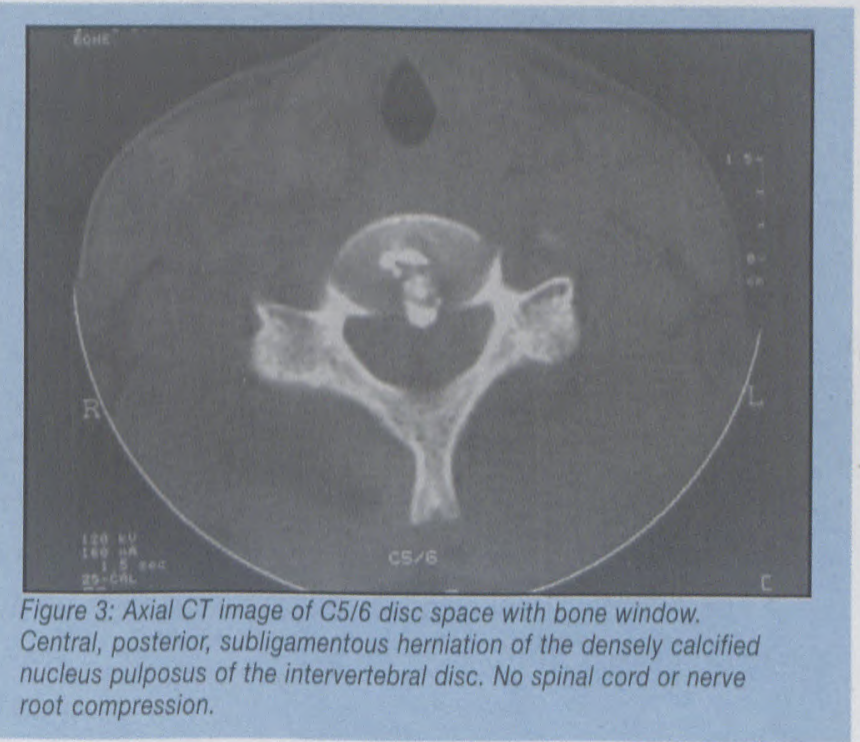

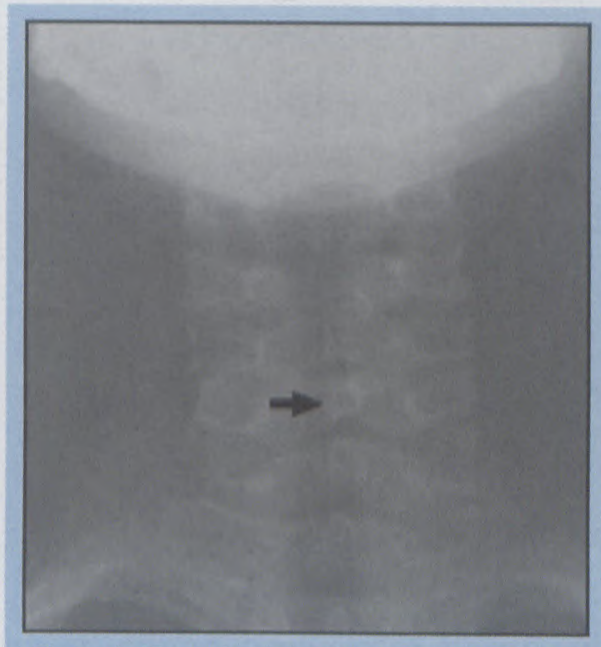

Figure 4: AP cervical spine follow-up x-ray. Normal alignment. Two, small, poorly visible calcifications (arrow) in the C5/6 intervertebral disc immediately to the right of the C5 spinous process.

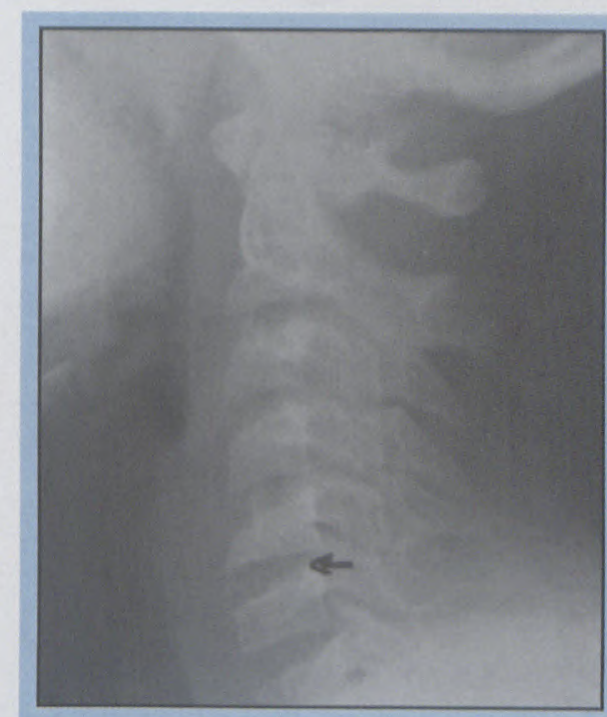

Figure 5: Lateral cervical spine follow-up view. Normal alignment. Multiple, poorly visible, small calcifications (arrow) scattered in the C5/6 intervertebral disc. Anterior wedging of the C5 vertebral body still present.

the $\mathrm{C} 5 / \mathrm{C} 6$ intervertebral disc was less easily visible, with multiple, small, poorly seen residual calcifications evident. The anterior wedging of the vertebral body of $\mathrm{C} 5$ was unchanged after three and a half months. The patient was considered to have been adequately treated, and was discharged from further follow-up. 
from page 9

\section{Discussion}

This case report is a good example of some of the characteristic clinical and imaging findings of symptomatic IVDC in the cervical spine in a child. Few conditions can mimic this presentation. $^{2}$

The incidence of IVDC is greater in boys than it is in girls. ${ }^{1,9,12,15-18}$ The affected age range varies from series to series - cervical IVDC has been described in young infants, ${ }^{1,2}$ including a premature newborn baby, ${ }^{19}$ with a maximum recorded age of 13 years. ${ }^{2,15,20}$ The peak age of presentation is between 5 to 10 years. ${ }^{2,4,}, 12,13,18$

Clinically, the patient with symptomatic cervical IVDC is usually in good health generally, and presents with an acute onset of severe neck pain and torticollis, accompanied by limited neck and head movement. . $^{1,2}$, $4-7,9,11,12,15-17,21-25$ Some patients will have evidence of inflammation ${ }^{1,2,4-7}$, $11,12,15,16,20,21,25$ with a low-grade fever at the onset of symptoms, possibly accompanied by a leucocytosis and raised ESR. 1, 2, 47 , 12, 15, 16, 20,25 Dysphagia may be present. ${ }^{1,2,4}$ If anterior herniation of the calcified disc occurs, it may be responsible for the dysphagia. ${ }^{16,26}$ The history of dysphagia in our patient was not associated with anterior disc herniation, but may rather have been related to the painful neck muscle spasm. Posterior disc protrusion or herniation can occur when the calcified nucleus pulposus herniates through the annulus fibrosis. The resultant disc deformity may not impinge on the spinal cord or cervical roots, as was the case in this patient. Should this occur, the patient may present with a painful upper limb radiculopathy. $1,2,4,7,15,16,20$ 22, 25, 27 The incidence of associated disc protrusion or herniation with cervical
IVDC is $30 \%$ to $38 \% .^{1,2,6,15,16,28}$ It is postulated that the greater mobility of the cervical spine predisposes to disc calcification and herniation. ${ }^{1}$ It is uncertain why the patients without disc herniation are symptomatic, but one explanation is that there may be a change in the hydrophilic properties of the calcified disc, raising intradiscal pressure and thereby producing symptoms. ${ }^{2,9,15}$

Patients with IVDC found co-incidentally on $\mathrm{x}$-ray $2,4-7,9,15,16,20$ represent either an asymptomatic or dormant form of the disorder. ${ }^{2,5}$ Curiously, patients with multiple levels of calcification are less likely to present with pain. ${ }^{2}{ }^{18}$ The incidence of asymptomatic patients is approximately 17 to $30 \%$. $6,13,16,20$

IVDC has been associated with congenital malformations such as cardiac and bone anomalies, but this is the exception rather than the rule. ${ }^{2,9,18}$

In children, intervertebral disc calcification occurs within the nucleus pulposus, whereas in adults disc calcification occurs in the annulus fibrosis ${ }^{1}$ $2,6,9,16$ The aetiology of the calcification in children remains uncertain $1,2,4$, $6-8,10,12,15,18,20,23$ Causes found in adults such as ochronosis, amyloidosis, acromegaly and metabolic defects such as chondrocalcinosis, hyperparathyroidism, hypervitaminosis $\mathrm{D}$, haemochromatosis, gout and pseudogout have not been implicated in children. 1, 2, 4, 6, 9, 12, 13, 15, 18, 20 Thirty to forty percent of symptomatic patients give a history of injury to the neck. ${ }^{1,2,4-6,15,20}$ Vertebral body fractures in children are not associated with IVDC., 1,5

The majority of IVDCs occur in the cervical spine ${ }^{1,2,4-6,12,13,15,16,20}$ and most frequently in the $\mathrm{C} 4$ to $\mathrm{C} 7$ area. $1,2,6,9$, ${ }^{10,15}$ The calcification usually involves a single cervical disc, but multiple calcified discs are recorded $1,2,5,6,9,12,13$, $15,16,20,21$ with a prevalence which is estimated to be 30 to $40 \%$ of all IVDC cases. ${ }^{2}$ The thoracic and lumbar discs may occasionally calcify in children, but IVDC in these regions is usually asymptomatic and the calcifications are not absorbed, remaining unaltered for many years. ${ }^{1,2,4,9,12,24,29}$ In the thoracic spine, disc protrusions are less likely to occur, possibly due to reduced thoracic mobility. In the lumbar spine, IVDC is found on the convex side of the curve in idiopathic scoliosis. ${ }^{1}$

Plain radiographs, CT and Magnetic Resonance Imaging (MRI) are the imaging modalities of choice for this condition. All three examinations show the IVDC located in the nucleus pulposus. The disc calcification usually occupies most of the disc space and has a round, oval ${ }^{1,9,16}$ or linear shape. ${ }^{4}$ Imaging may also demonstrate anterior wedging of the vertebral body adjacent to the calcified disc. 1, 2, 5, 6, 7,16, 25 Posterior wedging has also been documented. ${ }^{16} \mathrm{CT}$ and MRI are able to demonstrate the presence of calcified disc protrusion or herniation with or without spinal cord and/or nerve root involvement. ${ }^{1,4}$ Follow-up x-rays can be used to confirm the resolution of the calcification. A good case can be made for the use of plain $\mathrm{x}$-rays alone to make the initial diagnosis, ${ }^{20,24}$ and for CT to be restricted to investigating those patients with radiculopathy. ${ }^{20}$ Linear tomography of the spine is felt to be totally unnecessary. ${ }^{20}$

IVDC in children is usually a selflimiting disease with an excellent prognosis. ${ }^{1-4,} 6-8,10,11,15,16,18,20-24$ The clinical response to a regimen of nonsteroidal anti-inflammatory drugs, analgesics and a cervical collar 1,2, 4,9, $11,18,21,24$ is usually rapid, with the child becoming asymptomatic within days 


\section{from page 10}

to weeks $2,4,6,9,11,12,15,16,18,21$ as occurred in this patient. Rarely, the presence of the symptoms can be prolonged and the clinical condition can persist for months or years. ${ }^{2,9,30}$ The disc calcification gradually disappears within weeks to months, with minor radiographic abnormalities remaining. $1,2,4,6,12,15-17,18,20,21$ This is borne out in this patient, who showed almost total disappearance of the $\mathrm{C} 5 / 6$ IVDC and the persistence of anterior wedging of the $\mathrm{C} 5$ vertebral body, after three and a half months. Sometimes the IVDC can persist for years, but this is rare, $2,5,6,12,16,15,18$ On occasion, neck traction is required to aid response to conservative therapy. Surgery for disc herniation with cord and/ or nerve root compression has been recorded, but is rare. ${ }^{1-3,15,27}$ The recent trend is to persevere with conservative treatment, even with discrelated symptoms. There is increasing evidence that the clinical picture and radiculopathy in image-proven disc herniation with root or cord compression resolve with medical treatment and immobilisation. Surgical decompression should be reserved for patients who are refractory to conservative treatment. $2,4,6,7,28$

The intermediate-term changes which are recorded with IVDC take the form of loss of vertebral body height adjacent to the disc calcification, disc space narrowing at the involved site, scoliosis and osteophyte development. ${ }^{2,5,16}$ The long term consequences of IVDC are poorly documented, since patients are seldom closely followed into adulthood.

\section{References}

1. Ventura N, Huguet R, Salvador A Terricabras L, Cabrera AM. Intervertebral disc calcification in childhood. International Orthopaedics 1995; 19 (5): 291-294.

2. Mellion BT, Laurent JP, Watters WC Childhood intervertebral disc calcification. Child's Nervous System 1993; 9 (4): 233 238.

3. Mohanty S, Sutter B, Mokry M, Ascher PW. Herniation of calcified cervical intervertebral disc in children. Surgical Neurology 1992; 38 (6): 407-410.

4. Bhettay E, Joubert D, Meyers OL, Cremin B. Intervertebral disc calcification. Clinical Paediatrics 1992; 31 (7): 446-447.

5. Wong CC, Pereira B, Pho RW. Cervical disc calcification in children. A long term review. Spine 1992; 17 (2): 139-144

6. Dias MS, Pang D. Juvenile intervertebral disc calcification: recognition, management, and pathogenesis. Neurosurgery 1991; 28 (1): $130-135$.

7. Bradford R, Rice-Edwards M, Shawden $H$ Herniation of a calcified nucleus pulposus in a child: case report. British Journal of Neurosurgery 1989; 3 (6): 699-703.

8. Pattisapu JV, Evans OB, Blumenthal BI Intervertebral disc calcification in children. Pediatric Neurology 1987; 3 (2): 108-110.

9. Hahn YS, McLone DG, Uden D. Cervical intervertebral disc calcification in children. Child's Nervous System 1987; 3 (5): $274-$ 277.

10. McGregor JC, Butler P. Disc calcification in childhood: computed tomographic and magnetic resonance imaging appearances. British Journal of Radiology 1986; 59 (698): 180-182.

11. Pilliard D, Masse P, Taussig G. Intervertebral disc calcification in childhood. Rev Chir Orthop Reparatrice Appar Mot 1980; 66 (8): 515-521

12. Son Blomquist HK, Lindqvist M, Mattsson S. Calcification of intervertebral discs in childhood. Pediatric Radiology 1979; 8 (1): 23-26.

13. Henry MJ, Grimes HA, Lane JW. Intervertebral disc calcification in childhood. Radiology 1967; 89 (1): 81-84.

14. Baron A. Über eine neue erkrankung der wirbelsäule. Jahrb Kinderheilkd 1924; 104: 357-360.

15. Sonnabend DH, Taylor TKF, Chapman GK. Intervertebral disc calcification syndromes in children. Journal of Bone and Joint Surgery $1982 ; 64$ (1): 25-31.

16. Girodias JB, Azouz EM, Marton D. Intervertebral disc space calcification. Pediatric Radiology 1991; 21 (8): 541-546.
17. Jawish R, Rigault P, Padovani JP, Mouterde $P$, Touzet P, Chaumien JP. Intervertebral disc calcification in children. Rev Chir Orthop 1989; 75 (5): 308-317

18. Swick HM. Calcification of intervertebral discs in childhood. Journal of Pediatrics 1975; 86 (3): 364-369.

19. Ho PS, Ho KC, Yu S, et al. Calcification of the nucleus pulposus with pathologic confirmation in a premature infant. American Journal of Neuroradiology 1989; 10 (1): 201-202.

20. Ginalski JM, Landry M, Gudinchet F, Schnyder P. Is tomography of intervertebra disc calcification useful in children? Pediatric Radiology 1992; 22 (1): 59-61.

21. Zhang K, Dang G, Lou S. Cervical intervertebral disc calcification in children: report of 10 patients. Chung Hua Wai Ko Tsa Chih 1996; 34 (4): 197-200.

22. Causey AL, Evans OB, Lewis-Abney K Intervertebral disc calcification: an unusua cause of acquired torticollis in childhood Pediatric Emergency Care 1996; 12 (5): 356 . 359

23. Oulebsir A, Derdar T, Maiza EH, Khati B Calcification of the intervertebral discs in children apropos of a case. Pediatrie 1989; 44 (4): 327-329.

24. Herring JA, Hensinger RN. Cervical disc calcification. Journal of Pediatric Orthopaedics. 1988; 8 (5): 613-616.

25. Urso S, Colajacomo M, Migliorini A, Fassari FM. Calcifying discopathy in infancy in the cervical spine: evaluation of vertebral alterations over a period of time. Pediatric Radiology 1987; 17 (5): 387-391

26. Jawish R, Ponet M. Dysphagia disclosing a cervical disc calcification in a child. Apropos of a case and review of the literature. Chir Pediatric 1990; 31 (2): 127-130.

27. Oga M, Terada K, Kikuchi N, Oda Y, Sugioka $Y$. Herniation of calcified cervical intervertebral disc causes dissociated motor loss in a child. Spine 1993; 18 (15): 2347. 2350 .

28. Hoeffel JC, Bernard C, Schmit P, Denardaud L. Herniation of calcifying discopathy in childhood: report of three cases. European Journal of Pediatrics 1990; 149 (10): 695 697.

29. Bollini G, Bergoin M, Choux M, Padovani J. Disc calcifications in children. Apropos of 17 cases. Rev Chir Orthop Reparatrice Appar Mot 1984; 70 (5): 377-382.

30. Morris IM, Sheppard L. The persistence of clinical and radiological features after intervertebral disc calcification of childhood. British Journal of Rheumatology $1986 ; 25$ (2): 219-221. 